\title{
Intralaminar fracture toughness of UD glass fiber composite under high rate fiber tension and fiber compression loading
}

\author{
Peter Kuhn ${ }^{1, *}$, Hannes Koerber ${ }^{1}$, Giuseppe Catalanotti ${ }^{2}$, and José Xavier ${ }^{3,4}$ \\ ${ }^{1}$ Technical University of Munich, Department of Mechanical Engineering, Chair of Carbon Composites, Boltzmannstrasse 15, 85748 \\ Garching, Germany \\ ${ }^{2}$ School of Mechanical and Aerospace Engineering, Queen's University Belfast, United Kingdom \\ ${ }^{3}$ INEGI, Institute of Science and Innovation in Mechanical and Industrial Engineering, Rua Dr. Roberto Frias 400, 4200-465, Porto, \\ Portugal \\ ${ }^{4}$ CITAB, University of Tras-os-Montes e Alto Douro, UTAD, Quinta de Prados, 5000-801 Vila Real, Portugal
}

\begin{abstract}
Automotive and aeronautical composite structures can be subjected to dynamic loading scenarios (e.g. crash, bird strike). In both industrial areas, energy-based damage models for composite materials, able to predict initiation and evolution of damage of a composite ply under various loading conditions, are increasingly used. These models require the specification of fracture toughness parameters for the main failure modes. In previous works [1],[2], the authors have successfully enhanced a methodology suggested by Catalanotti et al. [3],[4] to measure the fiber failure crack resistance curves of a UD carbon fiber composite under dynamic loading. This methodology uses the relation between the energy release rate, the crack resistance curve and the size-effect law. For the determination of the size-effect law, double-edge-notched specimens of different sizes are tested. In this work, the developed approach is used for the measurement of the fracture toughness for fiber tension and compression failure of a UD glass-epoxy composite under high rate loading. Static tests are performed on an electromechanical test machine. For the high rate tests, split-Hopkinson bars for tensile (SHTB) and compressive (SHPB) loading are used. The results show, that the fracture toughness of the UD glass-epoxy composite, associated with the fiber failure modes, increases with increasing loading rate for tension as well as for compression. The observed strain rate effect on the fracture toughness of the glass-epoxy composite is more pronounced than for the carbon-epoxy composite investigated in [1],[2], in particular for fiber tensile failure.
\end{abstract}

\section{Introduction}

Recently proposed energy-based damage models and strength prediction methods for composite materials [5],[6],[7] require the specification of fracture toughness parameters associated with the main failure modes. In these models, the softening law for each failure mode is defined by the fracture toughness and related crack resistance curve (R-curve).

For the measurement of the fracture toughness associated with matrix failure, well established test standards are available (e.g. ASTM D5528 and ASTM D7905). To determine the fracture toughness for the energy-intensive fiber failure modes, compact tension (CT) and compact compression (CC) specimens are often used [8],[9].

The CC specimen however only provides an initiation value for the fiber compression fracture toughness, since the crack tip cannot easily be identified due to secondary damage mechanisms (e.g. delamination) [9]. With the CT specimen, stable crack propagation, required in the method for the determination of the R-curve, can usually be measured. Buckling and twisting or compressive failure

\footnotetext{
*e-mail: kuhn@lcc.mw.tum.de
}

at the back side, as well as failure at the load introduction points may however complicate the test.

Overcoming these limitations, Catalanotti et al. recently proposed to experimentally measure the R-curve and steady-state fracture toughness associated with fiber compressive and fiber tensile failure by using Double Edge Notched Compression (DENC) [3] and Double Edge Notched Tension (DENT) [4] specimens, respectively. The proposed method uses the relation between the size effect law, the energy release rate and the R-curve, as initially suggested by Bažant and Planas [10].

It is well known that composite materials exhibit a strong strain rate dependency. Strain rate dependent material behavior may therefore need to be considered for dynamically loaded composite structures.

The effect of strain rate on the elastic and strength properties has extensively been studied over the past decades by many researchers [11], [12] and continues to receive significant attention with new emerging composite materials and further enhancements of composite material models.

Also the effect of loading rate on the inter-laminar fracture toughness was the focus of many studies in the past. Published work in this area was summarized by Jacob et 
al. [13], concluding that there is no agreement on the trend of fracture toughness with regard to loading rate or on the best suitable method.

The study of the strain rate effect on the fracture toughness for the energy intensive fiber failure modes on the other hand has received very little attention.

The method proposed by Catalanotti et al. [3],[4], using various sizes of either DENC or DENT specimens, is very well suited for studying the effect of strain rate on the fiber compression and tension fracture toughness, since the specimens are comparably small and symmetric loading can be assured at both quasi-static and dynamic loading. This would not be the case when using the CT specimen geometry under dynamic loading, since the unsymmetrical opening of the CT specimen, caused by inertia effects, induces a mixed mode fracture in the specimen [14].

Using the DENC and DENT specimen geometry together with the size effect law, dynamic fracture toughness and R-curves for the fiber compression and fiber tension failure modes, were recently obtained for the unidirectional carbon-epoxy composite IM7-8552 by Kuhn et al. [1],[2]. For the investigated carbon-epoxy composite, a significant strain rate effect was found for the fiber compression fracture toughness, while a comparable small increase with increasing strain rate was found for fiber tension failure.

In this work, the developed dynamic test methodology is used to obtain the R-curve and steady-state fracture toughness for a unidirectional glass-epoxy composite under fiber tension and fiber compression loading at strain rates of about $120 \mathrm{~s}^{-1}$.

\section{Analysis scheme}

Following Bažant and Planas [10], for a so-called positive geometry, the energy release rate curves $G_{I k}$ for different specimen sizes $w_{k}$ at respective peak loads $P_{u k}$, are tangent to the R-curve $R$. Therefore, the R-curve is the envelope of the family of $G_{I k}$ curves, as illustrated in Fig. 1. The en-

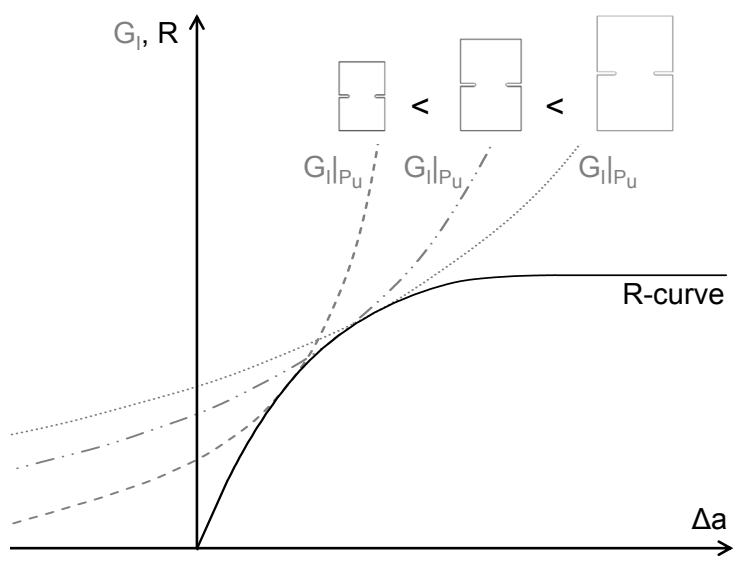

Fig. 1. Energy release rate curves $G_{I k}$ for different specimen sizes at respective peak load $P_{u k}$ and R-curve.

ergy release rate in a two-dimensional balanced crossply (with $x$ and $y$ as the preferred axes of the material) under tensile or compressive loading normal to the fracture surface (mode I) at the peak load can be written as [15]:

$$
G_{I}=\frac{1}{\grave{E}} w \sigma_{u}^{2} \kappa
$$

where $w$ is the characteristic specimen size and $\sigma_{u}$ is the ultimate nominal stress, which depends on the specimen size and is therefore described by the size effect law $\left(\sigma_{u}=\sigma_{u}(w)\right) . \kappa$ is the dimensionless correction function for orthotropy and geometry and can be calculated numerically on basis of the Virtual Crack Closure Technique as described in detail in [4]. $E$ is the equivalent modulus of the crossply laminate defined as [15]:

$$
\dot{E}=E\left(\frac{1+\rho}{2}\right)^{-1 / 2}
$$

where $E$ denotes the laminate Young's modulus and $\rho$ is the dimensionless elastic parameter defined as [15]:

$$
\rho=\frac{2 s_{12}+s_{66}}{2 \sqrt{s_{11} s_{22}}}
$$

in which $s_{l m}$ are the components of the compliance matrix computed in the $x-y$ coordinate system.

\section{Material and experimental procedures}

\subsection{Material and test specimens}

For the determination of the size effect law, crossply laminates, made from SAERTEX NCF E-Glass X-E-PB$627 \mathrm{~g} / \mathrm{m}^{2}-1270$ and Silka Biresin Epoxy CR80-CH80-2 were manufactured. Double-edge notched compression (DENC) and double-edge notched tension (DENT) specimens of different sizes were machined for the compressive and tensile tests, respectively, using a $1 \mathrm{~mm}$ diameter milling tool. A constant ratio of the geometric properties (free length $L$, width, initial crack length $a_{0}$ ) was held for all different specimen sizes (Fig. 2). The DENT specimens were glued into slotted endcaps with outside threads to attach them to the testing apparatuses.

Tab. 1 shows the elastic properties of the laminates under quasi-static (QS) and high strain rate $\left(\mathrm{HR}, \dot{\epsilon}_{s} \approx\right.$ $120 \mathrm{~s}^{-1}$ ) conditions.

Table 1. Elastic properties of the laminate.

\begin{tabular}{ccccccc}
\hline $\begin{array}{c}\text { Strain } \\
\text { rate }\end{array}$ & $\begin{array}{c}E_{c} \\
{[\mathrm{GPa}]}\end{array}$ & $\begin{array}{c}E_{t} \\
{[\mathrm{GPa}]}\end{array}$ & $\begin{array}{c}G_{x y} \\
{[\mathrm{GPa}]}\end{array}$ & $\begin{array}{c}v_{x y} \\
{[-]}\end{array}$ & $\begin{array}{c}\rho_{c} \\
{[-]}\end{array}$ & $\begin{array}{c}\rho_{t} \\
{[-]}\end{array}$ \\
\hline $\mathrm{QS}$ & 21.50 & 26.46 & 3.65 & 0.14 & 2.81 & 3.49 \\
$\mathrm{HR}$ & 21.50 & 30.37 & 3.51 & 0.15 & 2.92 & 4.17 \\
\hline
\end{tabular}

\subsection{Experimental setups}

The quasi-static (QS) reference tests were carried out on a standard electromechanical testing machine (Hegewald 
(a)
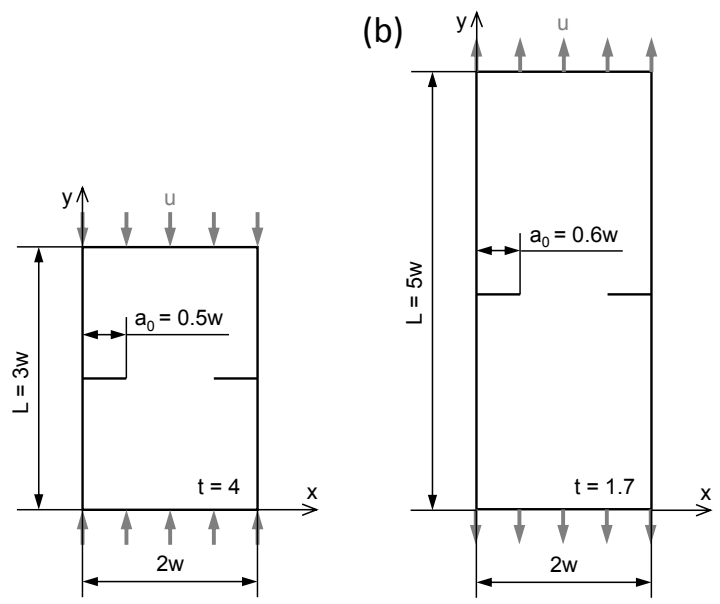

Fig. 2. Used DENC ( $w=5,7.5,10,12.5)$ (a) and DENT ( $w=4$, $6,8)($ b) specimen geometries.

\& Peschke Inspect Table 100) and a strain rate in the order of $2 \times 10^{-4} s^{-1}$ was obtained for all specimen types and sizes. For the compression tests, a self alignment system as described in [16] was used. The high strain rate (HR) compression and tension tests were performed on a split-Hopkinson pressure bar (SHPB) and split-Hopkinson tension bar (SHTB) system, respectively, as illustrated in Fig. 3.

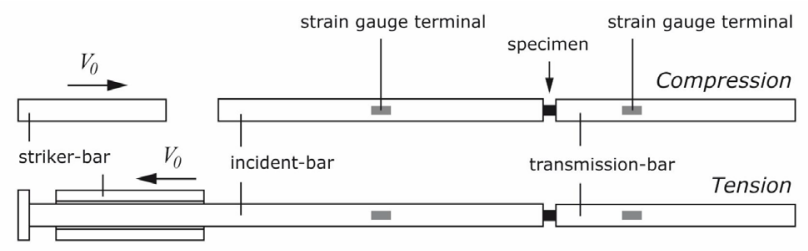

Fig. 3. SHPB setup (top) and SHTB setup (bottom) for high strain rate compression and tension tests.

The steel striker-, incident- and transmission bars of the SHPB system were $0.6,2.6$ and $1.3 \mathrm{~m}$ long, respectively. An U-shaped striker-bar of a length of $0.5 \mathrm{~m}$ was chosen for tests with the SHTB system, while the lengths of the titanium loading-, incident- and transmission-bars were $2.15,3$ and $1.8 \mathrm{~m}$, respectively. The bar diameters, $d_{b}$, striker-bar velocity , $v_{s}$, and pulse shaper dimensions were adapted to the tested specimen size either for the SHPB and SHTB setup to ensure that the axial strain rate was the same for every specimen size (Tabs. 2 and 3).

\subsection{Data reduction methods}

For the quasi-static tests, the ultimate remote stress, $\sigma_{u}$, was calculated by dividing the peak load, $P_{u}$, measured from the load cell of the testing machine, by the specimen cross-section, $A_{s}$, with $A_{s}=2 w t$ for the used DENC and DENT specimen geometries. In the case of the high rate tests, the axial stress component of the specimen, $\sigma_{s}$, can be calculated with the classic split-Hopkinson pressure bar
Table 2. Split-Hopkinson pressure bar parameters.

\begin{tabular}{cccccc}
\hline $\begin{array}{c}\text { Specimen } \\
\text { size }\end{array}$ & $\begin{array}{c}w \\
{[\mathrm{~mm}]}\end{array}$ & $\begin{array}{c}d_{b} \\
{[\mathrm{~mm}]}\end{array}$ & $\begin{array}{c}v_{s} \\
{[\mathrm{~m} / \mathrm{s}]}\end{array}$ & \multicolumn{2}{c}{$\begin{array}{c}\text { Pulse shaper } \\
{[\mathrm{mm}]}\end{array}$} \\
\hline $\mathrm{A}$ & 5 & 16 & 7.1 & 6 & 1.5 \\
$\mathrm{~B}$ & 7.5 & 18 & 8.2 & 8 & 2.0 \\
$\mathrm{C}$ & 10 & 18 & 9.7 & 10 & 2.0 \\
$\mathrm{D}$ & 12.5 & 25 & 10.7 & 10 & 2.0 \\
\hline
\end{tabular}

Table 3. Split-Hopkinson tension bar parameters.

\begin{tabular}{ccccl}
\hline $\begin{array}{c}\text { Specimen } \\
\text { size }\end{array}$ & $\begin{array}{c}w \\
{[\mathrm{~mm}]}\end{array}$ & $\begin{array}{c}d_{b} \\
{[\mathrm{~mm}]}\end{array}$ & $\begin{array}{c}v_{s} \\
{[\mathrm{~m} / \mathrm{s}]}\end{array}$ & Pulse shaper \\
\hline $\mathrm{A}$ & 4 & 16 & 5.1 & silicon rubber \\
$\mathrm{B}$ & 6 & 25 & 7.6 & silicon rubber \\
$\mathrm{C}$ & 8 & 25 & 9.9 & silicon rubber \\
\hline
\end{tabular}

analysis (SHPBA) $[17,18]$ by using 1-wave- and 2-waveanalysis:

$$
\begin{gathered}
\sigma_{s 1}=\frac{A_{b}}{A_{s}} E_{b} \varepsilon_{T} \\
\sigma_{s 2}=\frac{A_{b}}{A_{s}} E_{b}\left(\varepsilon_{I}+\varepsilon_{R}\right)
\end{gathered}
$$

where $A_{b}$ is the cross-section of the incident- and transmission-bar and $E_{b}$ is the Young's modulus of the bar material. $\varepsilon_{I}, \varepsilon_{R}, \varepsilon_{T}$ are the measured incident, reflected and transmitted bar strain waves, respectively. As both terms (Eq. 4, Eq. 5) were used to check specimen stressequilibrium, ultimate remote stress, $\sigma_{u}$, was calculated just from Eq. 4 due to the smooth transmitted wave signal.

\section{Experimental results}

At least three valid test were performed for each specimen type, specimen size and strain rate regime. The ultimate stress $\sigma_{u}$ vs. the specimen size $w$. is presented in Fig. 4 and Fig. 5. As a result of the size effect, the ultimate stress decreases with increasing specimen size at both investigated strain rate regimes and, furthermore, a pronounced strain rate effect can be measured for both compression and tension loading.

Stress equilibrium checks for a high rate loaded DENC and DENT specimen of size A are exemplary shown in Fig. 6 and Fig. 7, respectively. The existence of the stress equilibrium enables the use of the described analysis scheme (section 2), which is based on quasi-static fracture theory [19].

\section{Obtaining the R-curves}

On basis of the experimental results, the size effect law for the investigated glass-epoxy material under compression and tension loading can be expressed as [10]:

$$
\frac{1}{w \sigma_{u}^{2}}=\dot{m} \frac{1}{w}+\dot{q}
$$




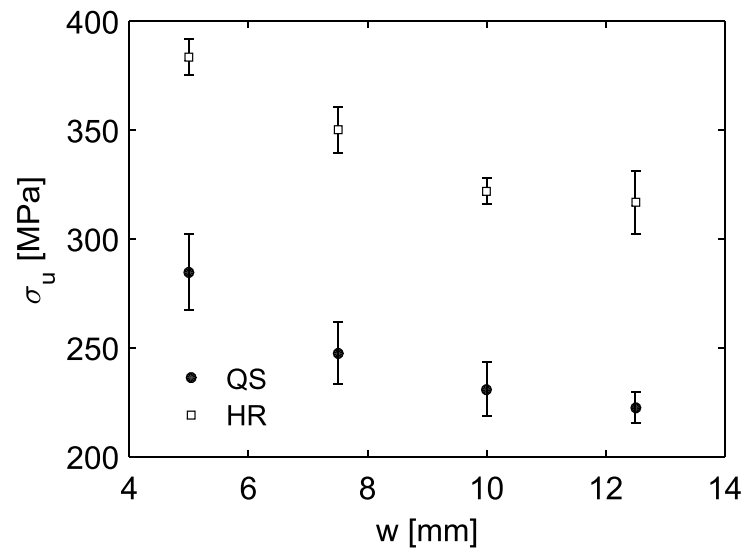

Fig. 4. Ultimate stress $\sigma_{u}$ vs. specimen size $w$ at both loading rate regimes for DENC specimens.

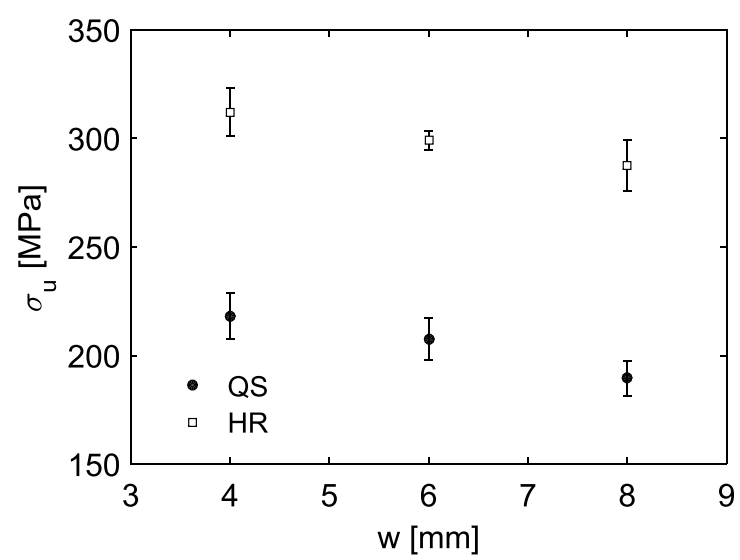

Fig. 5. Ultimate stress $\sigma_{u}$ vs. specimen size $w$ at both loading rate regimes for DENT specimens.

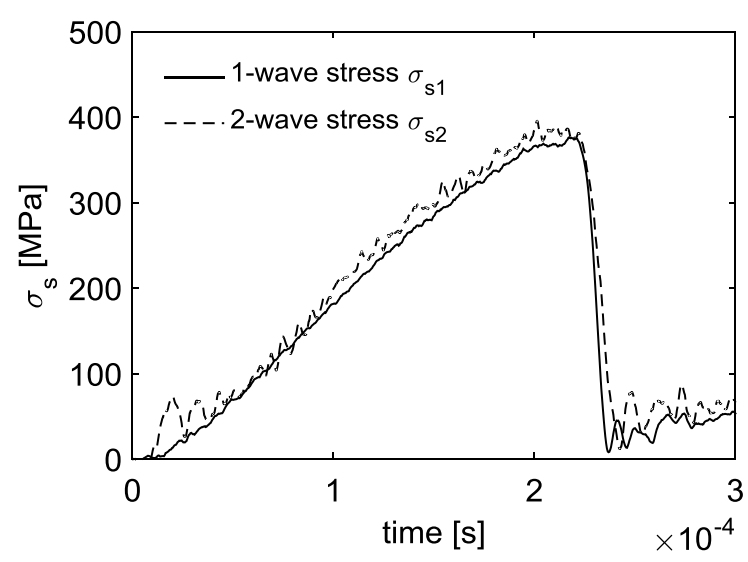

Fig. 6. Example of a dynamic equilibrium check for DENC specimens (specimen size A).

in which $\dot{m}$ and $q$ are the slope and the intercept of the linear curve fit respectively. In Fig. 8 and Fig. $9, \sigma_{u}^{-2} w^{-1}$ vs. $w^{-1}$ and the corresponding linear fitting curves are plotted. The curve fitting parameters are listed in Tab.4.

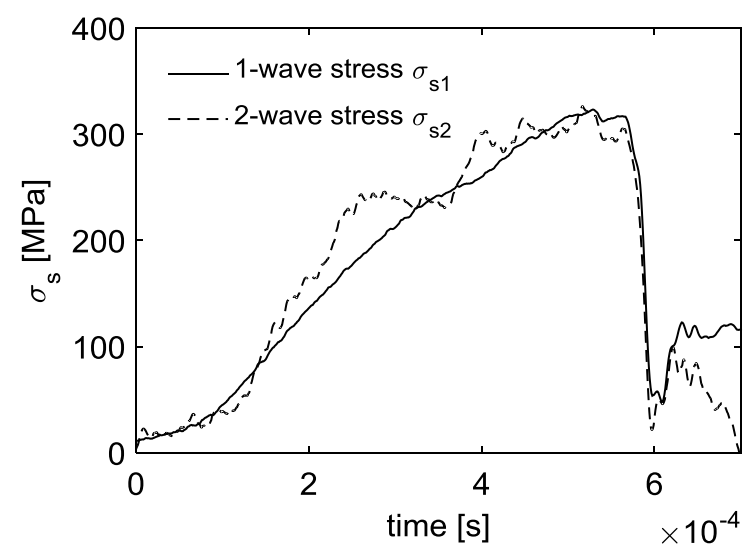

Fig. 7. Example of a dynamic equilibrium check for DENT specimens (specimen size A).

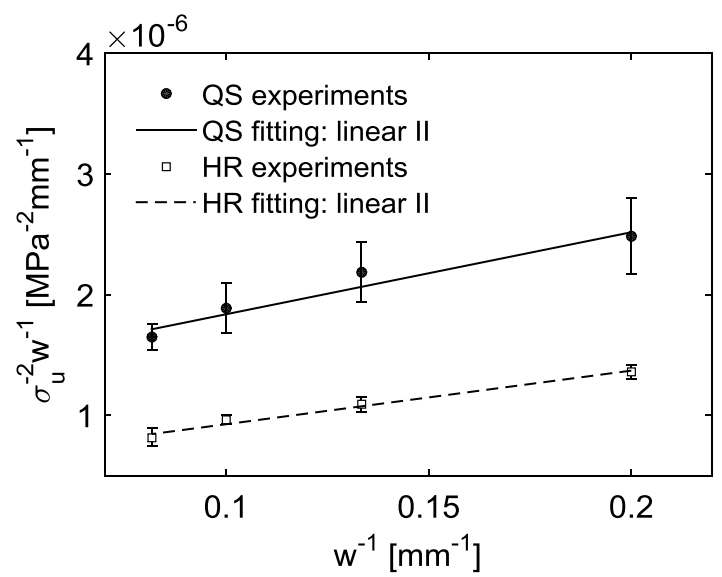

Fig. 8. $\sigma_{u}^{-2} w^{-1}$ vs. $w^{-1}$ and linear fitting at both loading rate regimes for DENC specimens.

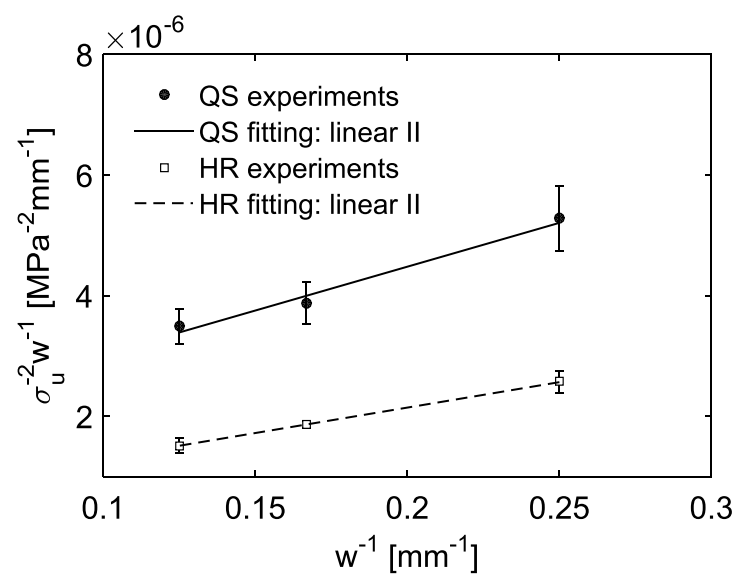

Fig. 9. $\sigma_{u}^{-2} w^{-1}$ vs. $w^{-1}$ and linear fitting at both loading rate regimes for DENT specimens.

Knowing the size effect law, the energy release rate curves $G_{I k}$ for different $w_{k}$ can be drawn, using Eq. 1. Finally, the R-curve of the laminate is the envelope of the family of curves of the energy release rate. For a balanced 
crossply, as used in this work, the R-curve of the $0^{\circ}$ plies $\left(R_{0}\right)$ is simply twice the value of $R$ [8]. The quasi-static and dynamic R-curves for the fiber compressive and fiber tensile failure of the investigated glass-epoxy are plotted in Fig. 10 and 11.

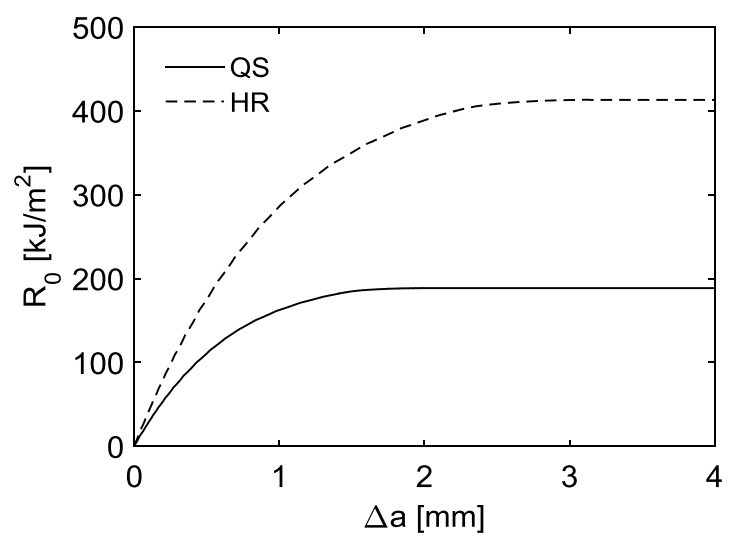

Fig. 10. Fiber compressive R-curves of the glass-epoxy for QS and HR loading.

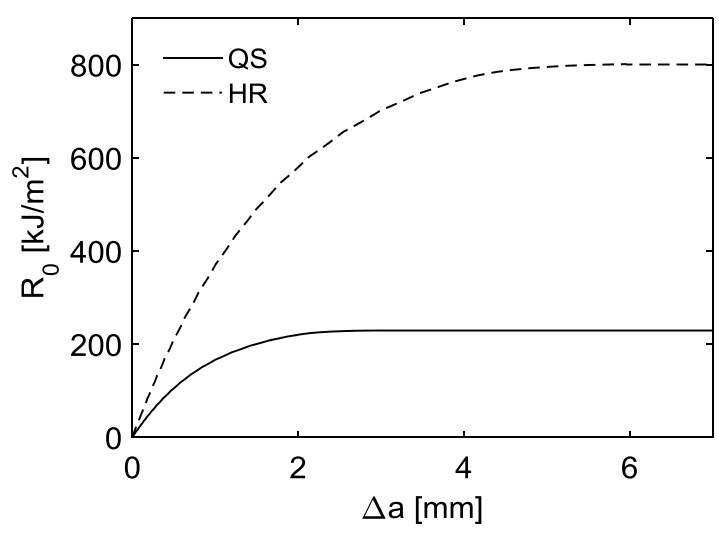

Fig. 11. Fiber tensile R-curves of the glass-epoxy for QS and HR loading.

The steady state value of the fracture toughness $R_{s s}^{0}$ can be obtained as [10]:

$$
R_{s s}^{0}=\lim _{w \rightarrow \infty} R_{0}=\frac{\kappa_{0}}{\dot{E}} \frac{1}{\dot{q}}
$$

where $\kappa_{0}=\left.\kappa\right|_{\alpha=\alpha_{0}}$. The values of $R_{s s}^{0}$ for both loading conditions and both strain rate regimes are summarized in Tab.4.

\section{Conclusion}

In this work the R-curves and steady-state fracture toughness for fiber compressive and fiber tensile failure of a unidirectional glass-epoxy composite were measured at quasi-static and dynamic strain rates $\left(\dot{\varepsilon}=120 s^{-1}\right)$.

The chosen double-edge-notched-compression (DENC) and double-edge-notched-tension (DENT) specimens
Table 4. Line coefficients of the size effect law and steady state fracture toughness $R_{s s}^{0}$.

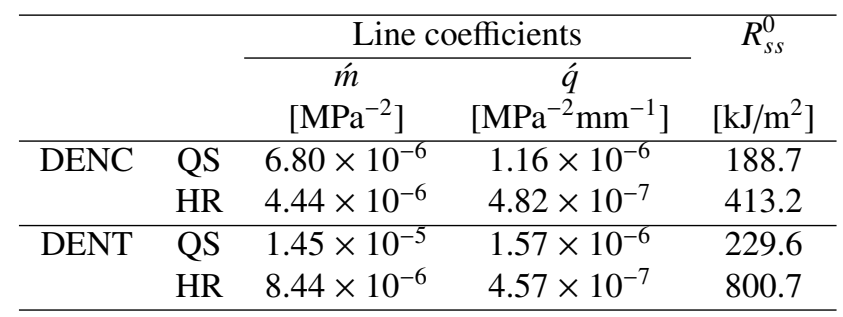

were well suited for dynamic tests using compression and tension split-Hopkinson bars, respectively.

Dynamic stress equilibrium was shown for both dynamic load cases, therefore allowing the use of quasi-static fracture theory.

The obtained results indicate that the fracture toughness of the investigated UD glass-epoxy composite increases with increasing loading rate under compressive as well as under tensile loading.

The observed strain rate dependency of the fracture toughness of the investigated UD glass-epoxy composite is more pronounced that for the UD carbon-epoxy recently investigated by the authors in [1] and [2], in particular for fiber tensile failure.

\section{References}

1. P. Kuhn, G. Catalanotti, J. Xavier, P.P. Camanho, H. Koerber, Composite Structures 182 164-175 (2017)

2. P. Kuhn, G. Catalanotti, J. Xavier, M. Ploeckl, H. Koerber, submitted to Composite Structures (2018)

3. G. Catalanotti, J. Xavier, P.P. Camanho, Composites Part A 56, $300 ? 307$ (2014)

4. G. Catalanotti, A. Arteiro, M. Hayati, P.P. Camanho, Engineering Fracture Mechanics 118, 49-65 (2014)

5. I. Lapczyk, J.A. Hurtado, Composites Part A 38, 2333 ?2341 (2007)

6. P. Maimi, P.P. Camanho, J.A. Mayugo, C.G. Davila, Mechanics of Materials 39909 ?919 (2007)

7. P.P. Camanho, G.H. Ercin, G. Catalanotti, S. Mahdi, P. Linde, Composites Part A 43 1219-1225 (2012)

8. S.T. Pinho, P. Robinson, L. Iannucci, Composites Science and Technology 66, 2069-2079 (2006)

9. G. Catalanotti, P.P. Camanho, J. Xavier, C.G. Davila, A.T. Marques, Composites Science and Technology 70 $1986 ? 93$ (2010)

10. Z.P. Bažant, J. Planas, Fracture and size effect in concrete and other quasibrittle materials (CRC Press LLC, Boca Raton, Florida, USA, 1998)

11. R.L. Sierakowski, Applied Mechanics Reviews 50 741-761 (1997)

12. G.C. Jacob, J.M. Starbuck, J.F. Fellers, S. Simunovic, R.G. Boeman, Journal of Applied Polymer Science 94 296-301 (2004) 
13. G.C. Jacob, J.M. Starbuck, J.F. Fellers, S. Simunovic, R.G. Boeman, Journal of Applied Polymer Science 96 899?904 (2005)

14. P. Beguelin, C. Fond, H.H. Kausch, International Journal of Fracture 89 85-102 (1998)

15. Z. Suo, G. Bao, B. Fan, T.C. Wang, International Journal of Solids and Structures 28, 235-248 (1990)

16. H. Koerber, J. Xavier, P.P. Camanho, Mechanics of Materials 42, 1004-1019 (2010)
17. H. Kolsky, Proc. Phys. Soc. London 62, 676-700 (1949)

18. G.T. Gray III, Classic split-Hopkinson pressure bar testing. In: ASM handbook mechanical testing and evaluation (ASM International, Ohio, USA, 2000)

19. F. Jiang, K.S. Vecchio, Applied Mechanics Reviews 62, 1-39 (2009) 